It has been frequently pointed out that there was no need and, in fact, no justification to assume that in this case the radiation was ever actually emitted at all. ${ }^{8}$ All that could be truly inferred from the experimental results was that an excited nucleus could either emit its excess energy as radiation or had some means of transferring this energy to the electronic structure of the atom.

On the old quantum mechanics, it was difficult to imagine any method other than that of radiation transfer, but the wave mechanics suggests that there is a far more intimate connexion between the nuclear particles and the electronic structure. The wave functions of the particles in the nucleus will extend out to a certain extent into the electronic region of the atom, and conversely the electronic wave functions will exist throughout the nucleus. As a model, we may think that every electron in the atom occasionally passes right through the nucleus, and that a nuclear particle might sometimes for a very short time be found to be actually outside the nucleus.

We have thus no difficulty in seeing, in a general way, how the nuclear energy might be transferred to the electronic system by a direct collision process. Which process, radiation or collision, is predominant can only be settled by experiment, and the answer given by experiment in this case is fortunately unambiguous. The measurements of Ellis and Aston ${ }^{5}$ of the extent of this internal conversion and of the way in which it depends on the fre. quency of the associated radiation show clearly that the behaviour is incompatible with the radiation hypothesis, and we are thus led to conclude that the collision process is the most important. It will be seen that this process is really a collision of the second kind, between an electron and an excited nucleus.

The peculiar interest of this phenomenon lies in the fact that it represents an easily measurable example of direct interaction between the nucleus and the electronic system. There are several other cases where the interaction between the nucleus and the electronic system must be taken into account, but only in order to give the finer details. The importance of the phenomenon of internal conversion is that the entire phenomenon, even to its first approximation, depends upon interaction, and that no approach can be made to it with a simple point nucleus.

However, quite apart from the intrinsic interest of this interaction, the phenomenon of internal conversion seems likely to provide valuable information about the stationary states in the nucleus. The quantity that can actually be measured, the internal conversion coefficient, is the ratio of the probabilities of occurrence of this collision of the second kind and of the nuclear radiation transition. The latter is determined mainly by the energy difference of the initial and final states, whilst the absolute energies are involved in the former. In a general way it can be seen that the internal conversion should lead to a classification of the levels responsible for the $\gamma$-rays, or, in other words, should enable the $\gamma$-rays to be associated with a definite part of the nucleus.

While but little has yet been accomplished along these various lines of investigation of the nuclear levels, it is certainly true that the most difficult step has already been made. The problem can now be clearly envisaged, and definite lines of work proposed which seem likely to lead to results. The way appears open to an experimental investigation of certain radioactive nuclei, and to an interpretation of the experimental results in terms of nuclear phenomena.

1 Rutherford and Andrade, Phil. Mag., 27, 854; 28, 262; 1924 Thibaud, Thèse, Paris, 1925. Frilly, Thèse, Paris, 1928. Meitner, Zeit. f. Physik, 52, 645; 1928 .

2 Steadman, Phys. Rev., 36, $460 ; 1930$

8 Ellis, Proc. Roy. Soc., A, 101, 1; 1922 . Thibaud, Thèse, Paris, 1925.

4 Skobeltzyn, Zeit. f. Physik., 43, 354 ; 1927 : 58, 595; 1929.

$s$ Ellis and Aston, Proc. Roy. Soc., A, 129, $180 ; 1930$.

- Gamow, Zeit. f. Physik, 51, 204; 1928. Gurney and Condon, NATURE, 122, $439 ; 1928$.

? Fowler, Proc. Roy. Soc., A, 129, 1 ; 1930

8 Smekal, Zeit. f. Physik, 10, 275; 1922, Ann. d. Phys., 81, 399 1926. Rosseland, Zeit. f. Physik, 14, 173; 1923.

\title{
An Institute for Experimental Research in Surgery.
}

$\mathrm{T}$ HANKS to the munificence of Mr. George Buckston Browne, the Council of the Royal College of Surgeons of England will be able to build, equip, and maintain an Institute for Experimental Research in Surgery, to be known by the donor's name. For the building and maintenance of such an Institute, and for the endowment of experimental research, Mr. Buckston Browne has

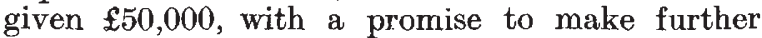
additions until a total of $£ 100,000$ is reached.

This munificent gift will give England what she now lacks-an institute where surgeons can carry out experimental research bearing on their art. The Institute is part of a scheme which was initiated by the Council of the College of Surgeons some years ago, when it equipped laboratories for surgical research in connexion with the Museum in Lincoln's Inn Fields. The workers now engaged in these laboratories have found that their investi- gations are crippled by the lack of a biological station or farm in the country where experimental animals can be maintained and observed under the best conditions. Mr. Buckston Browne's generosity makes the completion of the Council's scheme now possible.

It will be remembered that three years ago Mr. Buckston Browne acquired Down House, Kent, from Prof. C. G. Darwin, F.R.S., and after restoring and endowing it, presented it to the British Association to be preserved as a memorial to Darwin, and for such scientific purposes as the Council of the Association might determine. It was Mr. Buckston Browne's original intention to establish the Institute which is to bear his name on the grounds attached to Down House; but certain circumstances compelled an alteration of this plan. The chief of these was that the land lying to the west of the Down property and flanking

No. 3199, VoL. 127] 
Darwin's 'sand-walk' was to be opened up for building purposes. To save the adjacent fields from being built over, Mr. Buckston Browne stepped in and obtained the freehold of the property -13 acres in extent. It is this land which is to be the site of the Institute. It is possible that arrangements may be made whereby the new Institute and Down House may be linked so as to work together for the advancement of knowledge.

Mr. Buckston Browne has recalled the fact that John Hunter, the founder of the Museum of the Royal College of Surgeons, maintained a farm at Earl's Court for experimental purposes. He hopes that his Institute will be to modern surgeons what Earl's Court farm was to John Hunter.

Mr. George Buckston Browne, the donor, was born in Manchester in 1850, the only son of a well-known medical man-Dr. Henry Browne, physician to the Manchester Royal Infirmary and lecturer in medicine to the Manchester Medical School. Dr. Honry Browne represented the fourth generation of a medical dynasty where son had succeeded father the founder of the family having been Dr. Theophilus Browne, of Derby, who was townsman and contemporary of Dr. Erasmus Darwin, grandfather of Charles Darwin. $\mathrm{Mr}$. Buckston Browne continued the family tradition, representing the fifth medical generation. In 1866, at the age of sixteen, he matriculated as a student of the University of London, entered University College, was awarded medals in anatomy, chemistry, and midwifery, and gained the gold medal for practical chemistry and the Liston gold medal in surgery. He became a member of the Royal College of Surgeons in 1874, and gained in open competition the house-surgeoncy to his hospital (University College Hospital), where he served under Sir John Erichsen. He also taught anatomy under Prof. George Viner Ellis. No one ever trained himself more thoroughly for his profession. He is justly proud of the fact that the fortune which he now gives for the endowment of research in surgery has been gained in the zealous pursuit of his chosen profession.

\section{Obituary.}

Sir Andrew Balfour, C.B., K.C.M.G.

THE death of Sir Andrew Balfour on Jan. 30 at 1 the early age of fifty-seven years has deprived the world of one it can ill afford to lose. His remarkable knowledge of tropical medicine and hygiene, the result of years of practical experience in the field, research in the laboratory, and intensive study of the literature of the subject, had fitted him more than any other to be a leader and adviser in any movement concerned with the health of our great empire. Physically he was a powerfully built man of striking appearance, with open, clean-shaven face, searching blue eyes, and determined jaw ; and these attributes, combined with a remarkable personality embodying unbounded energy, enthusiastic devotion to duty, absolute honesty of purpose, and an irresistible appeal, brought him not only to the high position he held in his profession, but also at the same time into the hearts of everyone who knew him. His solicitude for the welfare of all, both high and low, who worked with him, and the personal interest he took in the aspirations or difficulties, whether great or small, of anyone who came to consult him, endeared him to a host of friends and admirers. From his early days he threw himself with fiery zeal into all he undertook to do or say.

As first director of the Wellcome Tropical Research Laboratories in Khartoum and medical officer of health of that city, and later, sanitary adviser to the Sudan Government, Balfour placed the medical and health services of the Sudan on a sound scientific basis. Later, he established the Welleome Bureau of Scientific Research in London, and commenced a graphic museum of tropical medicine which has developed into the Wellcome Museum of Medical Science. Finally, he directed the building and organisation of the London School of Hygiene and Tropical Medicine, a most difficult task, which brought him to the end of his career. The Great War found him with the Medical Advisory Committee, before and after which he made various tours of inspection in tropical lands.

Outside the partjcular sphere of his life's work, Balfour was an omnivorous reader, but biography, travel, and adventure pleased him most. He was a life-member of the Stevenson Club in London and Edinburgh, and took an active part in its proceedings. What appears to be only a few months ago, he gave one of his characteristic lectures, which in his modesty he entitled a " Gossip about Robert Louis Stevenson" He even found time to write books himself--books of adventure in his early day, such as " Cashiered, and other War Stories", "By Stroke of Sword ", "The Golden Kingdom ", and later, books and articles on public health and preventive medicine. Some of his articles, such as those collected in book form as "War Against Tropical Disease", were of a semi-popular nature and appealed to a wide public.

Balfour was an inspiring lecturer. He never failed to hold an audience by the charm of his language, the graphic pictures he would draw of what he had seen in his travels abroad, his earnest condemnation of what was bad and praise of what was good, and the sudden outbursts of wit and humour. To prepare his lectures he took endless trouble, which was often not apparent to those who listened to the easy flow of speech, always tinged with an accent indicative of his Scottish descent, of which he was supremely proud. In conversation, with his remarkable knowledge of many subjects, he had no equal, and, when in the mood, would recount his experiences or tell stories in a manner to fascinate his listeners for hours.

No account of his life would be complete with. out a reference to his passion for Rugby football A former Scottish international, he remained

No. 3199, VoL. 127] 